\title{
OPTIMIZATION OF CUTTING INSERT GEOMETRY USING DEFORM-3D: NUMERICAL SIMULATION AND EXPERIMENTAL VALIDATION
}

\author{
Tamizharasan, T. ${ }^{*} \&$ Senthil Kumar, N.** \\ *T.R.P. Engineering College, Tiruchirappalli, India \\ ** Anna University of Technology - Tiruchirappalli, Tiruchirappalli, India \\ E-Mail: engineering91@gmail.com,nskumar_1998@yahoo.co.in
}

\begin{abstract}
In this research work an attempt has been made to minimize flank wear of uncoated carbide inserts while machining AISI 1045 steel by finite element analysis. Tool wear is the predominant factor that causes poor surface finish and is responsible for the dimensional accuracy of the machined surface. The quality of component produced decides the effectiveness and competitiveness of any manufacturing industry. In this analysis, the effect of tool geometries on performance measures of flank wear, surface roughness and cutting forces generated are evaluated. Three levels of cutting insert shape, relief angle and nose radius are chosen. Taguchi's Design of experiment (DOE) is used to design the experiments. For three parameters and three levels a suitable $\mathrm{L}_{9}$ Orthogonal array is selected. Based on the designed experiment, simulation analysis is carried out using DEFORM-3D, a machining simulation and analysis software and the output quality characteristics are analysed by statistical techniques like Signal-to-Noise $(\mathrm{S} / \mathrm{N})$ ratio and Analysis of Variance (ANOVA). A validation finite element simulation is conducted with the obtained optimum tool geometry, which is also verified experimentally. It is observed that the performance of the determined tool geometry provides satisfactory results.

(Received in August 2011, accepted in November 2011. This paper was with the authors 1 month for 1 revision.)
\end{abstract}

Key Words: Tool Geometry, Flank Wear, FE Analysis, S/N Ratio, ANOVA, DEFORM-3D

\section{INTRODUCTION}

Machining is one of the most important and common manufacturing processes in industry. The efficiency and effectiveness of machining process can be increased, by continually improving the carbide cutting tool insert geometries. Machining a particular material under suitable machining conditions requires an optimal set of machining parameters and cutting tool geometry. The cutting life of carbide tool inserts can only be determined by cutting tests under real operating conditions. But model wear tests using finite element methods [1] would be very much useful for the pre-selection of machining parameters and tool geometries. The objective of this work is to study the effects of cutting insert geometries [2,3] like cutting insert shape, relief angle and nose radius $[4,5]$ on output response parameters. The machining parameters such as cutting speed, feed rate and depth of cut are kept constant. The various shapes of tools used for machining are shown in Fig. 1.

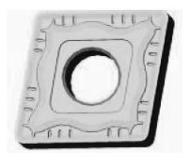

C Shape

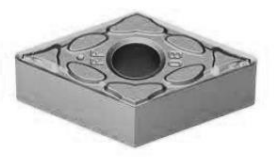

D Shape

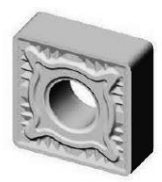

S Shape

Figure 1: Different shapes of cutting insert. 
Finite element simulation $[6,7]$ is carried out for various ISO designated cutting inserts modelled. The different cutting insert shapes selected are $\mathrm{C}$ (Diamond $80^{\circ}$ ), D (Diamond $55^{\circ}$ ) and $\mathrm{S}\left(\right.$ Diamond $90^{\circ}$ ), relief angle of $0^{\circ}, 3^{\circ}$ and $7^{\circ}$ and nose radius of $0.4 \mathrm{~mm}, 0.8 \mathrm{~mm}$ and 1.2 $\mathrm{mm}$. Various cutting inserts are selected as per ISO standards and the best cutting insert geometry is selected for better performance. For 3 parameters and 3 levels of value of each parameter, a $\mathrm{L}_{9}$ Orthogonal array is selected and the simulations are designed using Taguchi's Design of Experiments. Based on the formulated $\mathrm{L}_{9}$ Orthogonal array, finite element simulations are carried out using commercially available DEFORM-3D software [8, 9]. DEFORM is an engineering simulation software used to analyse various manufacturing processes, which forms an effective tool for research and industrial applications [10]. Using Signal-to-Noise ratio and Analysis of Variance, the output parameters like tool-chip interface temperature, tool-chip interface pressure, wear depth [11] and cutting forces [12] are analysed and an optimum cutting insert shape, relief angle and nose radius is determined. Using the optimum tool geometry, a validation simulation analysis is conducted and the results obtained are compared with the values determined from the experimental verification [13]. This analysis is important because, the increase in nose radius decreases the flank wear and the increase in relief angle reduces the contact area of insert with the machined surface, thereby decreasing the surface roughness. The included angle of the cutting tool decides the keenness of the cutting edge. This analysis can be implemented practically to improve the tool life and to decrease the costs associated with machining.

\section{LITERATURE REVIEW}

Much emphasis is given to tool life and flank wear since the dimensional accuracy and cost of the component produced will be affected by the nature of cutting tool. The tool life depends on the machining parameters and geometrical parameters which depend upon the type of process and material used. Arrazola et al. [1] presented a new approach involving the application of a variable friction coefficient at the tool-chip interface. Yung-Chang Yen et al. [2] analysed the effects of round/hone edge and T-land/chamfer edge upon the different output parameters during machining of AISI 1020 steel. Zouhar and Piska [3] presented that the increase of cutting forces are mainly due to rake angle, but an increase of tool edge radius results in lesser force increase. It has been found that the higher rake angle causes higher chip thickness, higher shear angle and with the modification of tool edge radius causes increase in internal contact energy. Ee et al. [4] evaluated the residual stresses in the machined component by thermal elastic-viscoplastic during finite element method. Gurbuz et al. investigated the influence of chip breaker geometry on tool stresses [5]. Ozel et al. [6] investigated the effects of multi-layered coated inserts while machining Ti-6Al-4V alloy using FEM analysis and compared the results with experimental data. Arrazola and Ozel [7] have compared the experimental results with two distinct FE model with ALE, fully coupled with thermal-stress analyses employed in simulation. Bil et al. [8] revealed the effects of friction, chip formation model and material data in plain strain orthogonal metal cutting simulation by comparing the results from MSC.Marc, Deform 2D and AdvantEDGE. Li and Shih [9] observed that, turning with a small depth of cut will produce good result in turning second grade pure titanium and investigated the chip segmentation with shear band formation. Attanasio et al. [11] modelled a heat transfer phenomena at the tool-chip interface and had implemented an analytical model by considering the diffusion wear mechanism. Qian and Hossan [12] studied the effects of cutting speed, feed, cutter geometry and workpiece hardness of different materials during machining with CBN tools and compared the results with experimental values. Maranhao and Davim [13] determined the influence of friction coefficient in tool chip interface by modelling the thermo mechanical behaviour while 
machining AISI 316 steel using triple layered carbide tool. Isik [14] investigated the effect of cutting fluids in turning processes. Neslusan et al. [15] analysed deformations after heat treatment and their influence on cutting process. Miguelez et al. [16] predicted the machininginduced residual stresses using FEM based Arbitrary Lagrangian Eulerian approach during machining AISI 316L in ABAQUS. Yen et al. [17] analysed the effects of round/hone edge and T-land/chamfer edge upon the different output parameters during machining of AISI 1020 steel. Duan et al. [18] studied the effects of rake angle and cutting forces in chip morphology using Johnson-cook material model based on ABAQUS during machining of AISI 1045 steel. Attanasio et al. [19] implemented a new analytical tool wear model, considering both abrasive and diffusive tool wear mechanism to forecast tool wear progression during machining using uncoated carbide tools. Ozel and Altan [20] used a flow stress model along with friction model to determine the flow stress in cutting zone and friction at tool-chip interface. Many researchers have chosen cutting inserts with different nose radii, coated cutting inserts and cutting inserts with different shapes. However, up to our knowledge, researchers have not considered this type of tool geometry for studying the performance of cutting inserts.

\section{FINITE ELEMENT METHOD}

In recent years, finite element analysis has become the main tool for simulating metal cutting processes. Simulation of machining test using Finite Element Analysis is particularly important due to time and cost consuming in the actual cutting test., hence it is preferred over experimental work. Moreover, the results obtained from the finite element analysis stays close to the results obtained from the experimental work. Finite element method is proved to be an effective technique for analysing chip formation processes and in predicting process variables such as temperatures, forces and stresses etc. The various ISO designated cutting inserts modelled using Solidworks are shown in Fig. 2.
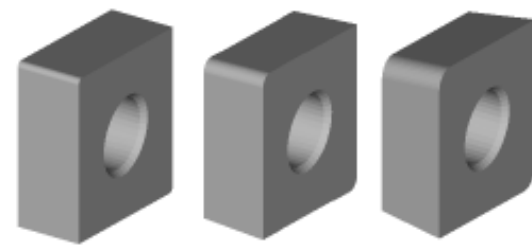

CNMG 120404

CAMG 120408

CCMG 120412
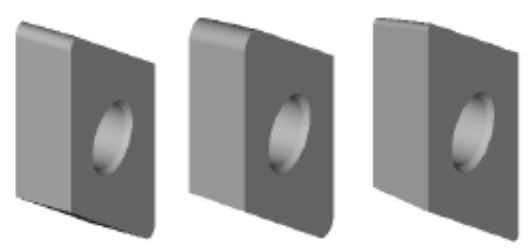

DNMG 150408

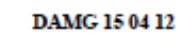

DCMG 150404
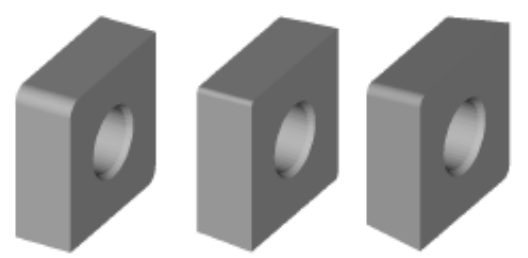

SNMG 120412

SAMG 120404

SCMG 120408

Figure 2: Modelled tools used for FEA analysis.

DEFORM-3D uses Usui's tool wear model to compute cutting inserts flank wear, which is used only with non-isothermal run as it requires interface temperature calculations. The initial 
temperature for the workpiece and tool is set as $30^{\circ} \mathrm{C}$ (room temperature). Simulations are carried out to reach the transient condition and then transformed to steady-state condition [16]. Tool stress analysis is performed to obtain maximum principal stresses acting on the cutting inserts. The cutting insert is a rigid object which turns a plastic workpiece. During simulation the length of workpiece to be machined is fixed. During meshing of cutting inserts, the number of tetrahedron elements is fixed as 30.000, while the number of elements in workpiece is kept at $25 \%$ of feed rate. During meshing, a finer mesh can be seen at the tool tip and in the workpiece, where the tool comes in contact with the workpiece. The tetrahedral mesh of uncoated carbide cutting insert and workpiece are shown in Fig. 3. The finite element analysis is performed on a computer with Intel Core i3, M350@2.27 GHz, 2 GB RAM, 32 bit operating system.
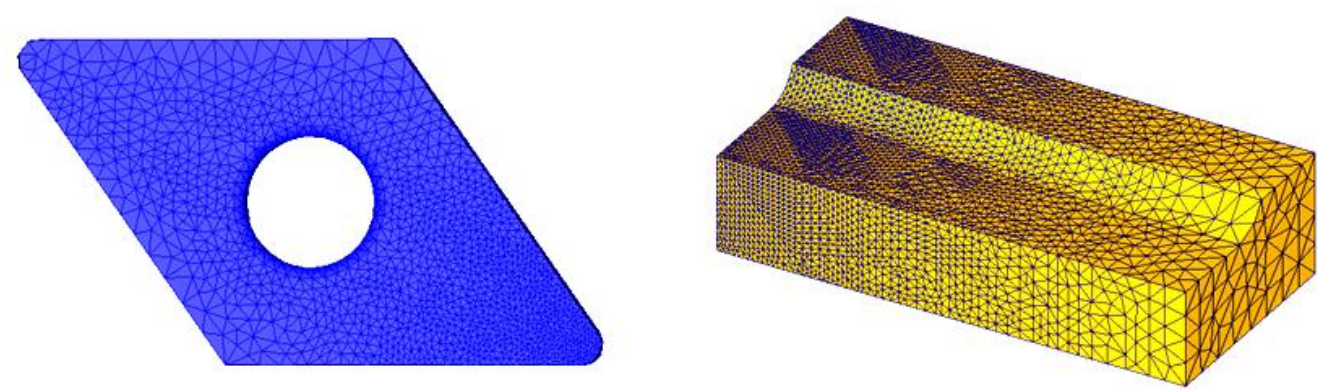

Figure 3: Tetrahedral mesh of tool and workpiece.

In Usui's tool wear model, the wear rate is a function of constant pressure, relative velocity and absolute temperature at the contact surface as given in Eq. (1):

$$
\frac{d w}{d t}=A \sigma_{u} V_{s} e^{(-B / T)}
$$

The constants of the wear rate model are taken as $A=0.0000000078$ and $B=5302$ [17].

\section{MATERIALS FOR CUTTING TOOL AND WORKPIECE}

The workpiece material used for the plane-strain orthogonal metal cutting simulation is AISI 1045 carbon steel [18]. AISI 1045 is a low cost alloy with adequate strength and toughness suitable for most of the engineering and construction applications, whose Brinell hardness value is $181 \mathrm{HB}$. Engineering applications of AISI 1045 steel includes shafts, pins, bolts, gears, forgings, cold drawing and extrusion. The chemical composition of the workpiece material is given in Table $\mathrm{I}$.

Table I: Chemical composition of AISI 1045 carbon steel (in \%).

\begin{tabular}{|c|c|c|c|c|c|c|c|c|c|c|c|c|}
\hline $\mathrm{C}$ & $\mathrm{Si}$ & $\mathrm{Mn}$ & $\mathrm{Cr}$ & $\mathrm{Mo}$ & $\mathrm{Ti}$ & $\mathrm{V}$ & $\mathrm{W}$ & $\mathrm{P}$ & $\mathrm{S}$ & $\mathrm{Cu}$ & $\mathrm{Al}$ & $\mathrm{Fe}$ \\
\hline 0.312 & 0.189 & 0.852 & 0.025 & 0.033 & 0.005 & 0.004 & 0.033 & 0.039 & 0.011 & 0.031 & 0.037 & Remainder \\
\hline
\end{tabular}

The optical image of the AISI 1045 steel is shown in Fig. 4. The microstructure of the matrix shows large grains of pearlite in a matrix of ferrite. The microstructure is typical of medium carbon steel that has been hot rolled and re-crystallized.

The material for cutting insert used for analysis is uncoated cemented carbide [19], whose material composition is given in Table II. 


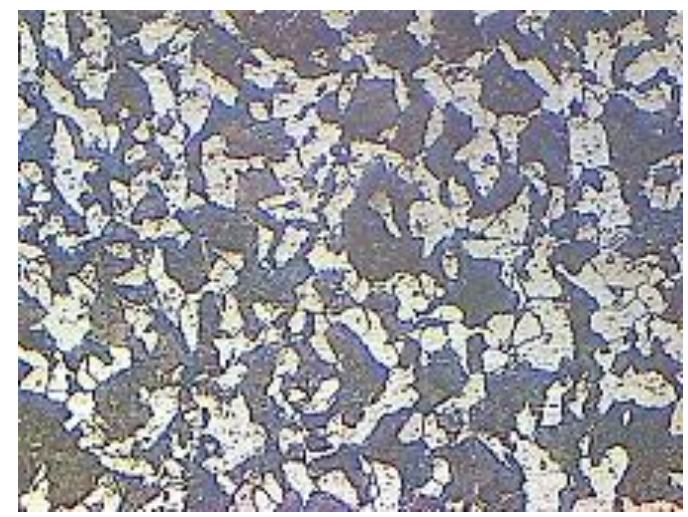

Figure 4: Optical image of AISI 1045 steel (100 X).

Table II: Chemical compositions of tungsten carbide insert.

\begin{tabular}{|c|c|c|c|c|}
\hline Tungsten carbide & Titanium carbide & Tantalum carbide & Molybdenum carbide & Cobalt \\
\hline $91-93.2 \%$ & $0.32 \%$ & $0.89-1.02 \%$ & Traces & $5.3-6.1 \%$ \\
\hline
\end{tabular}

Fig. 5 shows the SEM image of the uncoated cemented carbide cutting tool, where the tungsten carbide particles are embedded in a matrix of titanium carbide and tantalum carbide with cobalt as the binding material.

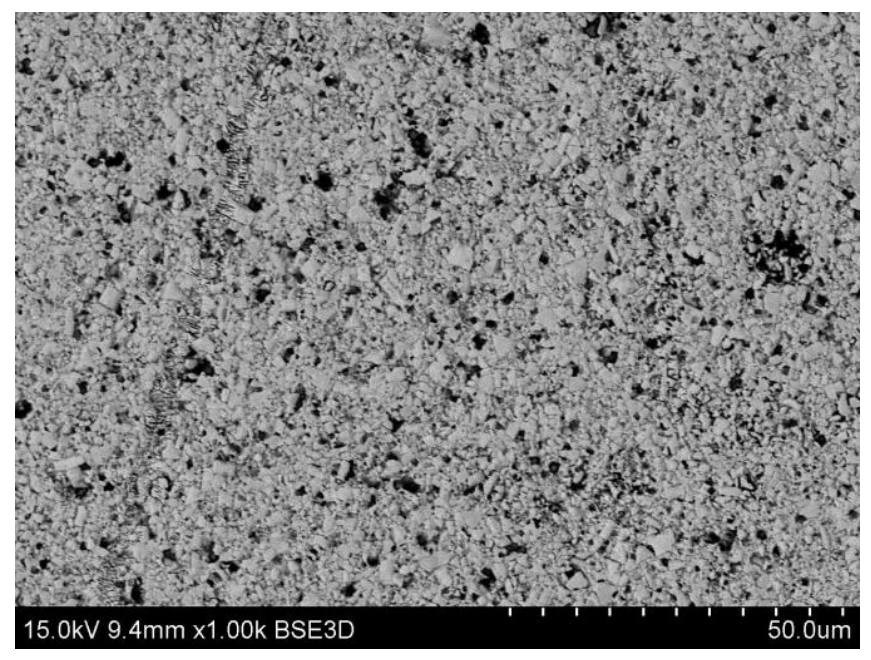

Figure 5: SEM image of cemented carbide insert.

\section{TAGUCHI'S TECHNIQUE}

Taguchi's technique is a powerful tool in quality optimization. Taguchi's technique makes use of a special design of orthogonal array (OA) to examine the quality characteristics through a minimal number of experiments. The experimental results based on the orthogonal array are then transformed into $\mathrm{S} / \mathrm{N}$ ratios to evaluate the performance characteristics. Taguchi's Design of Experiments is used to design the orthogonal array for 3 parameters varied through 3 levels. The control parameters and their levels chosen are shown in Table III. The minimum number of experiments to be conducted for the parametric optimization is calculated as,

$$
\text { Minimum experiments }=[(L-1) \times P]+1=[(3-1) \times 3]+1=7 \approx \mathbf{L}_{9}
$$


Table III: Control parameters and their levels.

\begin{tabular}{|c|c|c|c|c|}
\hline Parameter / Level & Symbol & Level 1 & Level 2 & Level 3 \\
\hline Cutting tool shape & $\mathrm{A}$ & $\mathrm{C}\left(80^{\circ}\right)$ & $\mathrm{D}\left(55^{\circ}\right)$ & $\mathrm{S}\left(90^{\circ}\right)$ \\
\hline Relief angle & $\mathrm{B}$ & $0^{\circ}$ & $3^{\circ}$ & $7^{\circ}$ \\
\hline Nose radius & $\mathrm{C}$ & $0.4 \mathrm{~mm}$ & $0.8 \mathrm{~mm}$ & $1.2 \mathrm{~mm}$ \\
\hline
\end{tabular}

The various combinations of cutting insert shapes, relief angle and nose radius, based on which the simulation analysis are conducted is shown in Table IV.

Table IV: Inner array of Taguchi L9 orthogonal array.

\begin{tabular}{|c|c|c|c|c|}
\hline Trial no. & Cutting insert shape & Relief angle $\left(^{\circ}\right)$ & Nose radius $(\mathrm{mm})$ & Insert designation \\
\hline 1 & $\mathrm{C}$ & 0 & 0.4 & CNMG 12 04 04 \\
\hline 2 & $\mathrm{C}$ & 3 & 0.8 & CAMG 12 04 08 \\
\hline 3 & $\mathrm{C}$ & 7 & 1.2 & CCMG 12 04 12 \\
\hline 4 & $\mathrm{D}$ & 0 & 0.8 & DNMG 15 04 08 \\
\hline 5 & $\mathrm{D}$ & 3 & 1.2 & DAMG 15 04 12 \\
\hline 6 & $\mathrm{D}$ & 7 & 0.4 & DCMG 15 04 04 \\
\hline 7 & $\mathrm{~S}$ & 0 & 1.2 & SNMG 12 04 12 \\
\hline 8 & $\mathrm{~S}$ & 3 & 0.4 & SAMG 12 04 04 \\
\hline 9 & $\mathrm{~S}$ & 7 & 0.8 & SCMG 12 04 08 \\
\hline
\end{tabular}

The machining parameters chosen are, cutting speed as $285 \mathrm{~m} / \mathrm{min}$, feed rate as 0.203 $\mathrm{mm} / \mathrm{rev}$ and depth of cut as $0.3 \mathrm{~mm}$ [21]. For analysis, there are 3 categories of performance characteristics, (i.e.) Smaller-is-the-better, Larger-is-the-better and Nominal-is-the-better.

- Smaller-is-the-better (Minimize):

$$
S / N=-10 \log \left(\frac{1}{n} \sum_{i=1}^{n} y_{i}^{2}\right)
$$

- Larger-is-the-better (Maximize):

$$
S / N=-10 \log \left(\frac{1}{n} \sum_{i=1}^{n} \frac{1}{y_{i}^{2}}\right)
$$

- Nominal-is-the-best:

$$
S / N=10 \log \left(\frac{\bar{y}}{s_{y}^{2}}\right)
$$

To obtain optimal machining performance, the response parameters like tool-chip interface [20] temperature, tool-chip interface pressure, wear depth and resultant cutting force has to be minimized. Hence the smaller-is-the-better performance characteristic for output parameters should be considered, which is given by Eq. (2).

\section{SIMULATION RESULTS AND DISCUSSION}

Based on the $\mathrm{L}_{9}$ orthogonal array, simulations are conducted to examine the effects of cutting insert shape, relief angle and nose radius. After performing the simulations, the output characteristics like tool-chip interface temperature, tool-chip interface pressure, wear depth and resultant cutting forces, which are determined, are tabulated in Table V. 
Table V: Control factors and quality characteristics of simulation analysis.

\begin{tabular}{|c|c|c|c|c|c|c|c|}
\hline \multirow{3}{*}{$\begin{array}{l}\text { Trial } \\
\text { no. }\end{array}$} & \multicolumn{7}{|c|}{ Outer array } \\
\hline & \multirow{2}{*}{$\begin{array}{c}\text { Interface } \\
\text { temperature } \\
\left({ }^{\circ} \mathrm{C}\right)\end{array}$} & \multirow{2}{*}{$\begin{array}{c}\text { Interface } \\
\text { pressure } \\
(\mathrm{MPa})\end{array}$} & \multirow{2}{*}{$\begin{array}{l}\text { Wear depth } \\
(\mathrm{mm})\end{array}$} & \multicolumn{3}{|c|}{ Cutting force $(\mathrm{N})$} & \multirow{2}{*}{$\begin{array}{l}\text { Resultant } \\
\text { force }(\mathrm{N})\end{array}$} \\
\hline & & & & $F_{x}$ & $F_{y}$ & $F_{z}$ & \\
\hline 1 & 615 & 9090 & $<0.0001$ & 34.372 & 323.96 & 54.039 & 330.23 \\
\hline 2 & 570 & 6150 & $<0.0001$ & 20.38 & 230.52 & 49.268 & 236.61 \\
\hline 3 & 565 & 9790 & $<0.0001$ & 32.647 & 387.56 & 66.20 & 394.53 \\
\hline 4 & 502 & 5990 & $<0.0001$ & 14.837 & 148.34 & 30.531 & 152.17 \\
\hline 5 & 516 & 6270 & $<0.0001$ & 18.20 & 217.07 & 26.768 & 219.47 \\
\hline 6 & 532 & 6580 & $<0.0001$ & 23.234 & 218.01 & 32.311 & 221.61 \\
\hline 7 & 500 & 21300 & $<0.0001$ & 10.975 & 400.69 & 32.32 & 402.14 \\
\hline 8 & 619 & 56800 & $<0.0001$ & 9.701 & 528.33 & 52.327 & 531.00 \\
\hline 9 & 534 & 9660 & $<0.0001$ & 3.420 & 434.94 & 36.89 & 436.51 \\
\hline
\end{tabular}

Using Minitab-16, statistical software, the analysis is carried out. Using Smaller-is-thebetter technique of Signal-to-Noise ratio, the combined $\mathrm{S} / \mathrm{N}$ ratio is determined, which is shown in Table VI.

Table VI: Combined S/N ratio of the output quality characteristics.

\begin{tabular}{|c|c|c|c|c|c|}
\hline \multirow{2}{*}{$\begin{array}{c}\text { Trial } \\
\text { no. }\end{array}$} & \multicolumn{4}{|c|}{ Outer array } & \multirow{2}{*}{} \\
\cline { 2 - 5 } & $\begin{array}{c}\text { Interface } \\
\text { temperature } \\
\left({ }^{\circ} \mathrm{C}\right)\end{array}$ & $\begin{array}{c}\text { Interface } \\
\text { pressure } \\
(\mathrm{MPa})\end{array}$ & $\begin{array}{c}\text { Wear depth } \\
(\mathrm{mm})\end{array}$ & $\begin{array}{c}\text { Resultant } \\
\text { force }(\mathrm{N})\end{array}$ & $\begin{array}{c}\text { Combined } \\
\text { S/N ratio }\end{array}$ \\
\hline 1 & 615 & 9090 & $<0.0001$ & 330.23 & -73.176 \\
\hline 2 & 570 & 6150 & $<0.0001$ & 236.61 & -69.800 \\
\hline 3 & 565 & 9790 & $<0.0001$ & 394.53 & -73.817 \\
\hline 4 & 502 & 5990 & $<0.0001$ & 152.17 & -69.561 \\
\hline 5 & 516 & 6270 & $<0.0001$ & 219.47 & -69.959 \\
\hline 6 & 532 & 6580 & $<0.0001$ & 221.61 & -70.377 \\
\hline 7 & 500 & 21300 & $<0.0001$ & 402.14 & -80.551 \\
\hline 8 & 619 & 56800 & $<0.0001$ & 531.00 & -89.067 \\
\hline 9 & 534 & 9660 & $<0.0001$ & 436.51 & -73.701 \\
\hline
\end{tabular}

Based on the combined $\mathrm{S} / \mathrm{N}$ ratio the response table for the 3 levels of input parameters such as cutting insert shape, relief angle and nose radius are determined, as shown in Table VII.

Table VII: Response Table of S/N ratio.

\begin{tabular}{|c|c|c|c|}
\hline Level / Parameter & Insert shape & Relief angle & Nose radius \\
\hline 1 & -72.26 & -74.43 & -77.54 \\
\hline 2 & -69.97 & -76.28 & -71.02 \\
\hline 3 & -81.11 & -72.63 & -74.78 \\
\hline Max - Min & 11.14 & 3.64 & 6.52 \\
\hline
\end{tabular}


From the response table, the main effects plot of $\mathrm{S} / \mathrm{N}$ ratio are drawn for cutting insert shape, relief angle and nose radius, which are shown in Fig. 6.
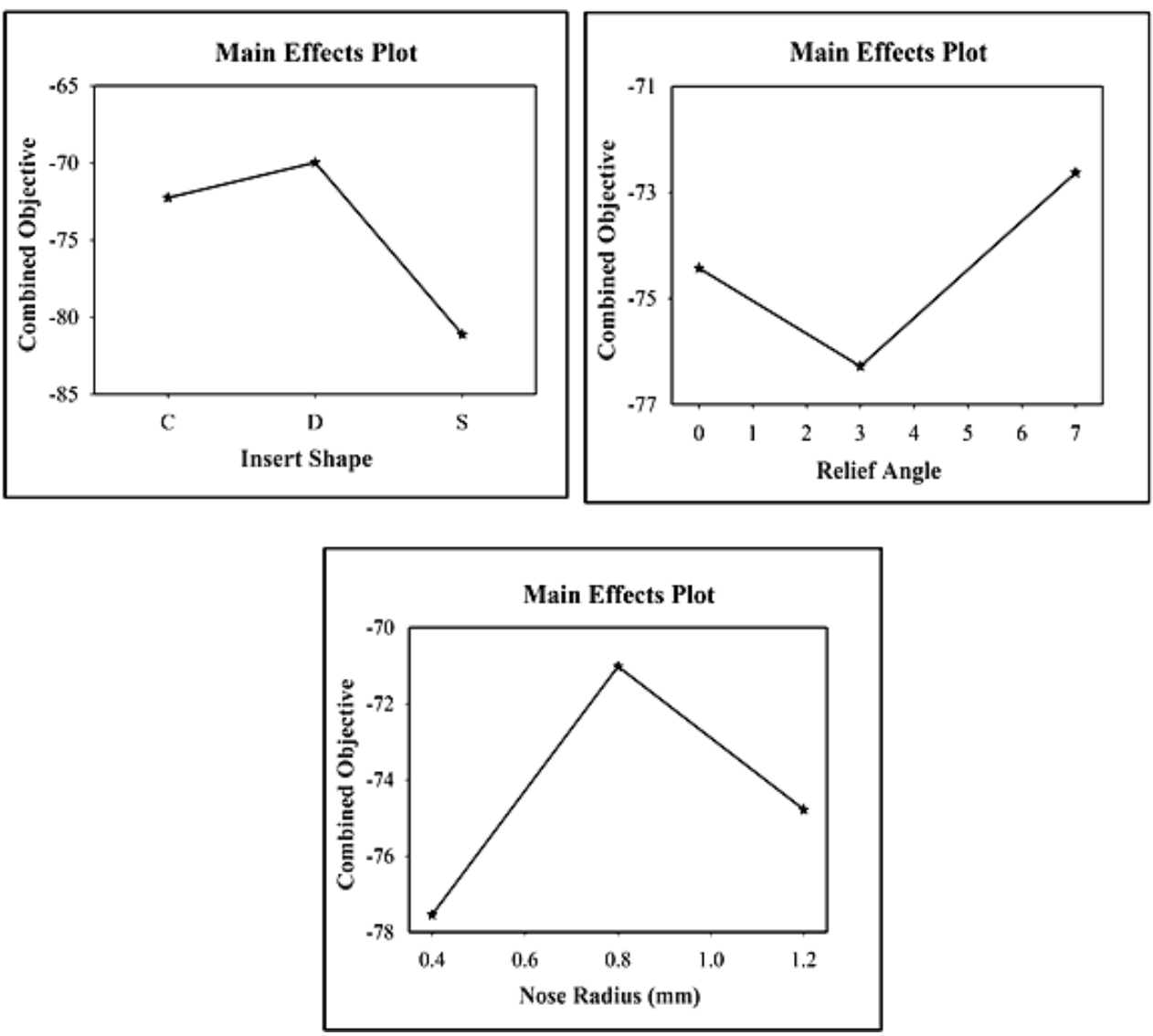

Figure 6: Main effects plot of $\mathrm{S} / \mathrm{N}$ ratio.

From the response table of $\mathrm{S} / \mathrm{N}$ ratio, the best level of parameters are identified as Cutting insert shape of $\mathrm{D}\left(\right.$ Diamond $\left.55^{\circ}\right)$, relief angle of $7^{\circ}$ and nose radius of $0.8 \mathrm{~mm}\left(\mathrm{~A}_{2} \mathrm{~B}_{3} \mathrm{C}_{2}\right)$.

Analysis of Variance is an important technique for analysing the effect of categorical factors on a response. An ANOVA decomposes the variability in the response variable amongst the different factors. Depending upon the type of analysis, it may be important to determine: which factors have a significant effect on the response, and how much of the variability in the response variable is attributable to each factor. For determining the significant factor, which contribute more, ANOVA table is formulated, which is given in Table VIII.

Table VIII: ANOVA for S/N ratio.

\begin{tabular}{|c|c|c|c|c|c|c|c|}
\hline Source & $D F$ & Seq SS & \multicolumn{1}{c|}{ Adj SS } & Adj $M S$ & $F$ & $P$ & \% Contribution \\
\hline Insert shape & 2 & 207.58 & 207.58 & 103.788 & 4.72 & 0.175 & $\mathbf{6 1 . 8 3}$ \\
\hline Relief angle & 2 & 19.92 & 19.92 & 9.960 & 0.45 & 0.688 & 5.93 \\
\hline Nose radius & 2 & 64.24 & 64.24 & 32.121 & 1.46 & 0.407 & $\mathbf{1 9 . 1 3}$ \\
\hline Residual error & 2 & 44.00 & 44.00 & 22.002 & & & 13.11 \\
\hline Total & 8 & 335.74 & & & & & \\
\hline
\end{tabular}

From the ANOVA, it is evident that the cutting insert shape is the significant factor, which contributes $61.83 \%$, followed by nose radius $19.13 \%$. The relief angle does not have any significant contribution. 


\section{FEA AND EXPERIMENTAL VALIDATION}

With the identified optimum tool geometry, a new tool is modelled using SOLIDWORKS and a validation simulation analysis is conducted and the quality characteristics obtained are shown in Table IX.

Table IX: Output quality characteristics of optimal tool geometry.

\begin{tabular}{|c|c|c|c|c|c|c|}
\hline $\begin{array}{c}\text { Interface } \\
\text { temperature }\end{array}$ & \multirow{2}{*}{$\begin{array}{c}\text { Interface } \\
\text { pressure }\end{array}$} & \multirow{2}{*}{$\begin{array}{c}\text { Wear depth } \\
(\mathrm{mm})\end{array}$} & \multicolumn{3}{|c|}{ Cutting force $(\mathrm{N})$} & \multirow{2}{*}{$\begin{array}{c}\text { Resultant } \\
\text { force (N) }\end{array}$} \\
\cline { 4 - 7 } & $(\mathrm{MPa})$ & & $F_{x}$ & $F_{y}$ & $F_{z}$ & \\
\hline 486 & 9640 & $<0.0001$ & 31.26 & 318.08 & 50.709 & 323.61 \\
\hline
\end{tabular}

Fig. 7 shows the chip formation during turning AISI 1045 steel with optimum tool geometry. The load acting on the cutting insert shows that, initially the loads acting on the cutting insert is high, which is stabilized with further machining.

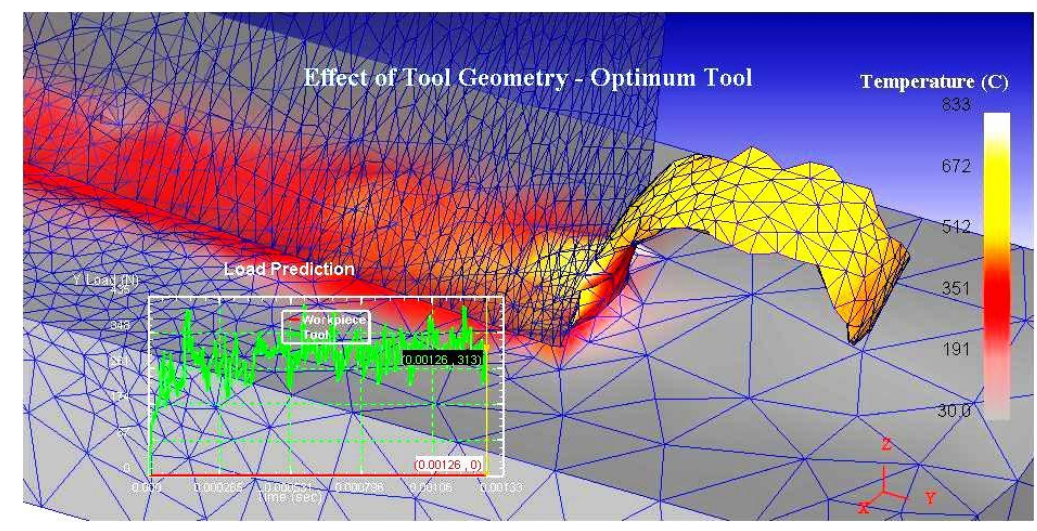

Figure 7: Machining with optimum insert.

Fig. 8 shows the distribution of cutting forces acting on the cutting insert. It is observed that the maximum cutting forces are acting at the cutting edge, where the cutting insert gets into contact with workpiece.

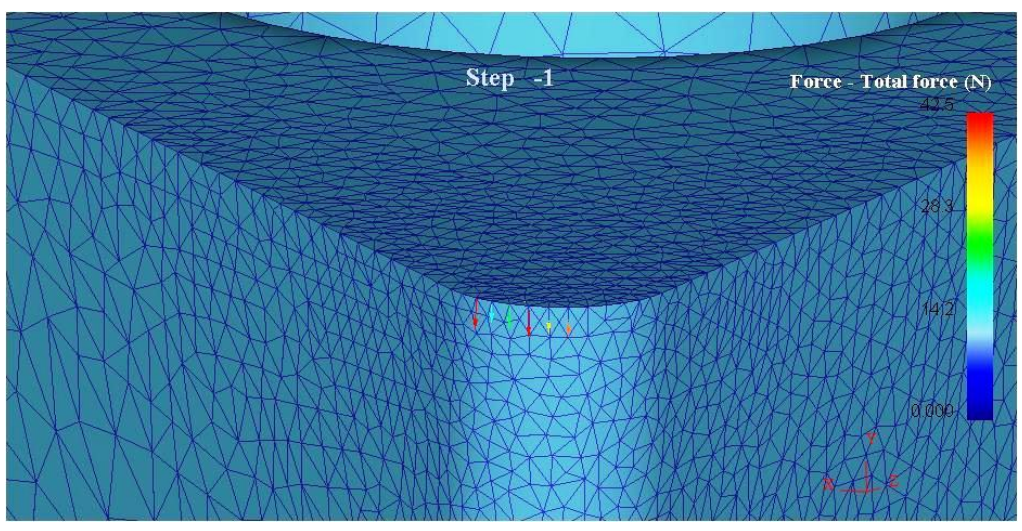

Figure 8: Distribution of cutting forces in optimum cutting tool.

Fig. 9 shows the maximum principal stresses acting on the cutting insert. It is visualized that the concentration of stress is more on the edge of the cutting insert, where the cutting action takes place during turning. 


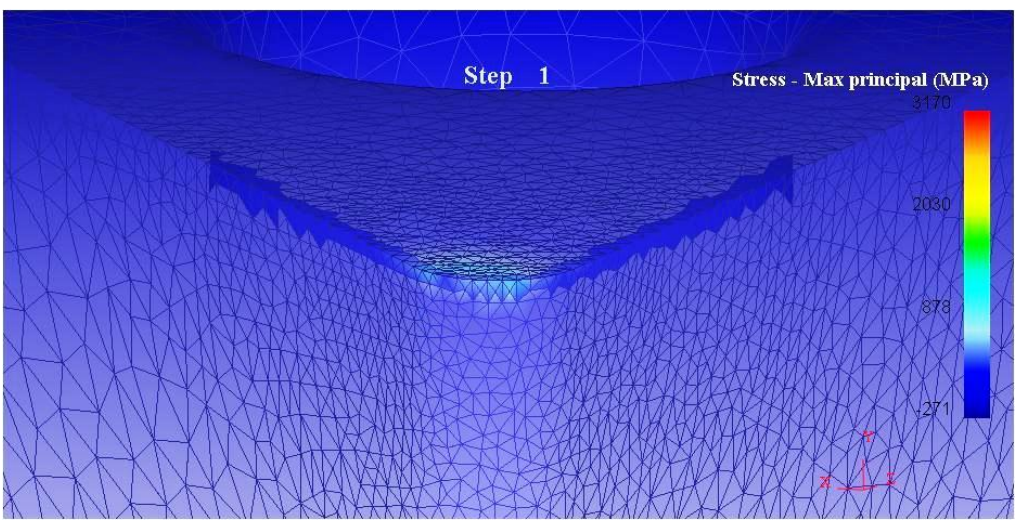

Figure 9: Maximum principal stress in optimum tool.

Experimental verification is carried out to determine the tool wear, surface roughness of the machined surface and associated cutting forces generated during machining. CNC turning centre, with swing diameter of $350 \mathrm{~mm}$, spindle speed $4500 \mathrm{rpm}$, main motor power of $11 \mathrm{~kW}$ is used. After performing the machining process, the flank wear is measured and recorded by using a Mitutoyo digital tool maker's microscope of specifications, eyepiece 15X, objective $2 \mathrm{X}$, total magnification 30X. Surface roughness values of the machined surfaces are recorded by using a Kosaka Laboratory Ltd make Surfcorder SE1200; with a vertical measuring range of $520 \mu \mathrm{m}$, horizontal measuring range of $25 \mathrm{~mm}$. Generated cutting forces are measured using Kistler Lathe tool dynamometer attached to the CNC turning centre. Table X shows the experimental validation output values.

Table X: Experimental validation output.

\begin{tabular}{|c|c|c|c|c|c|}
\hline \multirow{2}{*}{$\begin{array}{l}\text { Flank } \\
\text { wear } \\
(\mathrm{mm})\end{array}$} & \multirow{2}{*}{$\begin{array}{c}\text { Surface } \\
\text { roughness } \\
(\mu \mathrm{m})\end{array}$} & \multicolumn{3}{|c|}{ Cutting force $(\mathrm{N})$} & \multirow{2}{*}{$\begin{array}{l}\text { Resultant } \\
\text { force }(\mathrm{N})\end{array}$} \\
\hline & & $F_{x}$ & $F_{y}$ & $F_{z}$ & \\
\hline 0.537 & 1.763 & 291.23 & 154.21 & 108.84 & 347.05 \\
\hline
\end{tabular}

Fig. 10 shows the surface roughness profile of the machined surface of AISI 1045 steel, using the Optimum tool geometry. It is observed that the waviness produced on the surface is almost uniform.

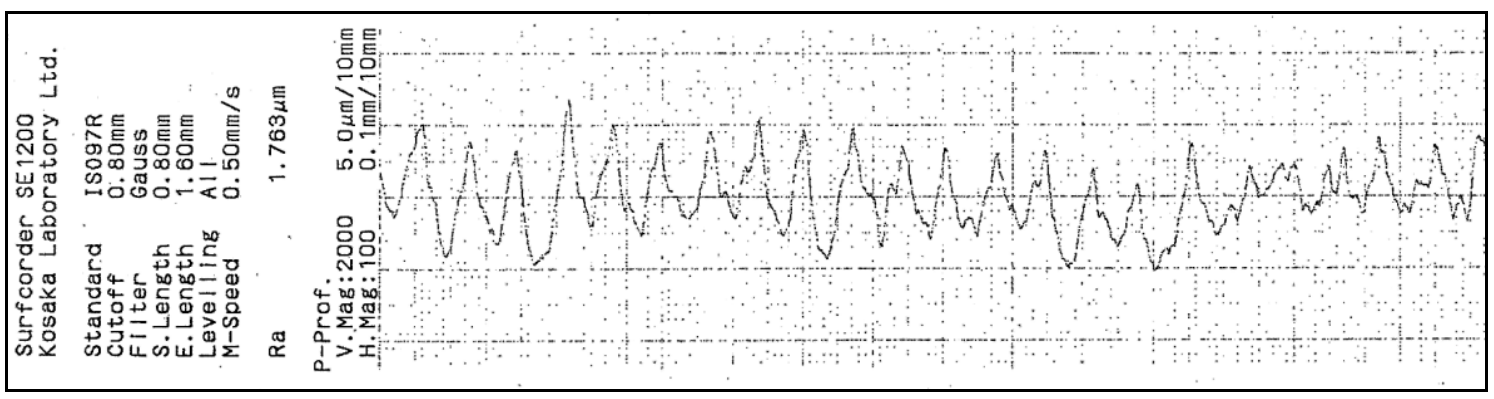

Figure 10: Surface roughness profile of validated specimen.

\section{CONCLUSION}

From the simulation results obtained from the Finite Element Analysis using Deform-3D, it is concluded that, 
1. The optimum condition obtained is cutting insert shape $\mathrm{D}$ (Diamond $55^{\circ}$ ), relief angle of $7^{\circ}$ and nose radius of $0.8 \mathrm{~mm}$. i.e., DCMG 150408 .

2. For ' $\mathrm{D}$ ' Shape, the interface temperatures, interface pressure, wear depth and resultant cutting forces are minimum.

3. It has been seen that the for ' $\mathrm{D}$ ' Shape, relief angle of $0^{\circ}$ and nose radius of $0.8 \mathrm{~mm}$, the interface temperatures, interface pressure, wear depth and resultant cutting forces are the least among the nine designed tools.

4. As the nose radius increases, the wear depth decreases and the cutting forces also decreases.

5. For $7^{\circ}$ relief angle, the interface temperature and interface pressure are minimum when compared to that of other two relief angles.

6. Finite element and experimental validation shows a lower flank wear and cutting forces with a moderate surface roughness.

7. Hence it is concluded that for machining AISI 1045 steel, the cutting insert with less included angle with a nominal relief angle and medium nose radius will be beneficial.

8. In the future, more tool geometrical parameters will be considered to improve the performance of cutting inserts.

\section{REFERENCES}

[1] Arrazola, P. J.; Ugarte, D.; Dominguez, X. (2008). A new approach for the friction identification during machining through the use of finite element modeling, International Journal of Machine Tools \& Manufacture, Vol. 48, No. 2, 173-183, doi:10.1016/j.ijmachtools.2007.08.022

[2] Yen, Y.-C.; Jain, A.; Altan, T. (2004). A finite element analysis of orthogonal machining using different tool edge geometries, International Journal of Materials Processing Technology, Vol. 146, No. 1, 72-81, doi:10.1016/S0924-0136(03)00846-X

[3] Zouhar, J.; Piska, M. (2008). Modelling the orthogonal machining process using cutting tools with different geometry, MM science Journal, October, 48-51

[4] Ee, K. C.; Dillon Jr., O. W.; Jawahir, I. S. (2005). Finite element modeling of residual stresses in machining induced by cutting using a tool with finite edge radius, International Journal of Mechanical Sciences, Vol. 47, No. 10, 1611-1628, doi:10.1016/j.ijmecsci.2005.06.001

[5] Gurbuz, H.; Kurt, A.; Ciftci, I.; Seker, U. (2011). The Influence of Chip Breaker Geometry on Tool Stresses in Turning, Strojniški vestnik - Journal of Mechanical Engineering, Vol. 57, No. 2, 91-99, doi:10.5545/sv-jme.2009.191

[6] Ozel, T.; Sima, M.; Srivastava, A. K.; Kaftanoglu, B. (2010). Investigations on the effects of multi-layered coated inserts in machining $\mathrm{Ti}-6 \mathrm{Al}-4 \mathrm{~V}$ alloy with experiments and finite element simulations, CIRP Annals - Manufacturing Technology, Vol. 59, 77-82. doi:10.1016/ j.cirp.2010.03.055

[7] Arrazola, P. J.; Ozel, T. (2010). Investigations on the effects of friction modeling in finite element simulation of machining, International Journal of Mechanical Sciences, Vol. 52, 31-42, doi:10.1016/j.ijmecsci.2009.10.001

[8] Bil, H.; Kilıc, S. E.; Tekkaya, E. A. (2004). A comparison of orthogonal cutting data from experiments with three different finite element models, International Journal of Machine Tools \& Manufacture, Vol. 44, No. 9, 933-944, doi:10.1016/j.ijmachtools.2004.01.016

[9] Li, R.; Shih, A. J. (2006). Finite element modeling of 3D turning of titanium, International Journal of Advanced Manufacturing Technology, Vol. 29, No. 3-4, 253-261, doi:10.1007/s00170-005-2511-6

[10] Cep, R.; Janasek, A.; Martinicky, B.; Sadilek, M. (2011). Cutting tool life tests of ceramic inserts for car engine sleeves, Technical Gazette, Vol. 18, No. 2, 203-209

[11] Attanasio, A.; Ceretti, E.; Rizzuti, S.; Umbrello, D.; Micari, F. (2008). 3D finite element analysis of tool wear in machining, CIRP Annals - Manufacturing Technology, Vol. 57, No. 1, 61-64, doi:10.1016/j.cirp.2008.03.123 
[12] Qian, L.; Hossan, M. R. (2007). Effect of cutting force in turning hardened tool steels with cubic boron nitride inserts, International journal of materials processing technology, Vol. 191, No. 1-3, 274-278, doi:10.1016/j.jmatprotec.2007.03.022

[13] Maranhao, C.; Paulo Davim, J. (2010). Finite element modeling of machining of AISI 316 steel: Numerical simulation and experimental validation, International Journal of Simulation Modelling Practice and Theory, Vol. 18, No. 2, 139-156, doi:10.1016/j.simpat.2009.10.001

[14] Isik, Y. (2010). An Experimental Investigation on Effect of Cutting Fluids in Turning with Coated Carbides Tool, Strojniški vestnik - Journal of Mechanical Engineering, Vol. 56, No. 3, 195-201

[15] Neslusan, M.; Mrkvica, I.; Cep, R.; Kozak, D.; Konderla, R. (2011). Deformations after heat treatment and their influence on cutting process, Technical Gazette, Vol. 18, No. 4, 601-608

[16] Miguelez, M. H.; Munoz-Sanchez, A.; Cantero, J. L.; Loya, J. A. (2009). An Efficient Implementation of Boundary Conditions in an ALE model for Orthogonal Cutting, Journal of Theoretical and Applied Mechanics, Vol. 47, No. 3, 599-616

[17] Yen, Y.-C.; Sohner, J.; Lilly, B.; Altan, T. (2004). Estimation of tool wear in orthogonal cutting using the finite element analysis, Journal of Materials Processing Technology, Vol. 146, No. 1, 82-91, doi:10.1016/S0924-0136(03)00847-1

[18] Duan, C. Z.; Dou1, T.; Cai, Y. J.; Li, Y. Y. (2009). Finite Element Simulation and Experiment of Chip Formation Process during High Speed Machining of AISI 1045 Hardened Steel, International Journal of Recent Trends in Engineering, Vol. 1, No. 5, 46-50

[19] Attanasio, A.; Ceretti, E.; Fiorentino, A.; Cappellini, C.; Giardini, C. (2010). Investigation and FEM-based simulation of tool wear in turning operations with uncoated carbide tools, Wear, Vol. 269, No. 5-6, 344-350, doi:10.1016/j.wear.2010.04.013

[20] Ozel, T.; Altan, T. (2000). Determination of workpiece flow stress and friction at the chip-tool contact for high-speed cutting, International Journal of Machine Tools \& Manufacture, Vol. 40, No. 1, 133-152, doi:10.1016/S0890-6955(99)00051-6

[21] Oberg, E.; Jones, F. D.; Horton, H. L.; Ryffel, H. H. (2008). Machinery's Handbook, 28 ${ }^{\text {th }}$ Edition, Industrial Press, New York 